\title{
Scale dependence of plant species richness and vegetation-environment relationship along a gradient of dune stabilization in Horqin Sandy Land, Northern China
}

\author{
XiaoAn ZUO ${ }^{1,2^{*}}$, ShaoKun WANG ${ }^{1,2}$, XueYong ZHAO ${ }^{1,2}$, Jie LIAN $^{1,2}$ \\ ${ }^{1}$ Naiman Desertification Research Station, Cold and Arid Regions Environmental and Engineering Research Institute, Chinese \\ Academy of Sciences, Lanzhou 730000, China; \\ ${ }^{2}$ Laboratory of Stress Ecophysiology and Biotechnology, Cold and Arid Regions Environmental and Engineering Research \\ Institute, Chinese Academy of Sciences, Lanzhou 730000, China
}

\begin{abstract}
Ecological patterns and processes in dune ecosystems have been a research focus in recent years, however the information on how dune stabilization influences the spatial scale dependence of plant diversity is still lacking. In this study, we measured the plant species richness, soil properties and altitude across four spatial scales $\left(1,10,100\right.$ and $\left.1,000 \mathrm{~m}^{2}\right)$ at three different dune stabilization stages (mobile dune, semi-fixed dune and fixed dune) in Horqin Sandy Land, Northern China. We also examined the relationships between plant species richness, community composition and environmental factors along the gradient of dune stabilization. Our results showed that plant species richness increased with the increase of spatial scales in each dune stabilization stage, as well as with the increase of dune stabilization degrees. Canonical correspondence analysis (CCA) showed that plant distributions in the processes of dune stabilization were determined by the combined environmental gradient in relation to soil organic carbon $(\mathrm{SOC})$, total nitrogen $(\mathrm{TN})$, carbon/nitrogen $(\mathrm{C} / \mathrm{N}), \mathrm{pH}$, electrical conductivity $(\mathrm{EC})$, soil water content (SWC), fine sand (FS), very fine sand (VFS), silt and clay (SC), and altitude. Plant species richness was significantly and positively correlated to SOC and TN in mobile dune, and significantly and positively correlated to SOC, TN, C/N, VFS and SC in semi-fixed dune. However, no significant correlation between plant species richness and environmental factors was observed in fixed dune. In addition, plant species richness in different dune stabilization stages was also determined by the combined gradient of soil properties and altitude. These results suggest that plant species richness has obvious scale dependence along the gradient of dune stabilization. Soil resources depending on dune habitats and environmental gradients caused by dune stabilization are important factors to determine the scale dependence of species diversity in sand dune ecosystems.
\end{abstract}

Keywords: CCA; environmental gradient; sandy land ecosystem; spatial scale dependence; species diversity

Citation: XiaoAn ZUO, ShaoKun WANG, XueYong ZHAO, Jie LIAN. 2014. Scale dependence of plant species richness and vegetation-environment relationship along a gradient of dune stabilization in Horqin Sandy Land, Northern China. Journal of Arid Land, 6(3): 334-342. doi: $10.1007 / \mathrm{s} 40333-013-0221-8$

Species richness in arid and semi-arid ecosystems is spatial scale dependent (Crawley and Harral, 2001; He et al., 2006; Palmer, 2006). Understanding how species richness varies with spatial scales is very important to improve our ability to conserve biodiversity and to manage ecosystems (Palmer and White, 1994;
Turner and Tjorve, 2005; He et al., 2006). Species-area relationships are one of the most studied ecological patterns in assessing the response of plants to environmental stress (Cantero et al., 1998; Weiher and Howe, 2003; Palmer, 2006). The study of ecosystems has always been highly influenced by the spatial

\footnotetext{
*Corresponding author: XiaoAn ZUO (E-mail: zuoxa@lzb.ac.cn) Received 2013-03-07; revised 2013-04-07; accepted 2013-06-16

(C) Xinjiang Institute of Ecology and Geography, Chinese Academy of Sciences, Science Press and Springer-Verlag Berlin Heidelberg 2014
} 
scale at which the research of vegetation patterns responding to different environmental factors is conducted (Weiher and Howe, 2003; He et al., 2006; Schooley, 2006; Auestad et al., 2008). Thus the influence of environmental factors and spatial scales on the variations in plant diversity and community composition is very important for understanding ecological patterns and processes.

Many studies on the relationships between vegetation composition and environmental factors have been carried out in arid and semi-arid ecosystems (Chiarucci et al., 2001; He et al., 2007; Auestad et al., 2008; Wana and Beierkuhnlein, 2011). Soil and topography are thought to exert important influences on vegetation composition at landscape (Kirkpatrick and Bridle, 1999; Marini et al., 2008; Qian et al., 2008; Petersen and Drewa, 2009) and smaller scales (Caballero et al., 2008; Zuo et al., 2008). Some studies have revealed that vegetation composition is mainly determined by a moisture gradient controlled by elevation, slope degree, and soil texture (Moustafa and Zaghloul, 1996), as well as by a combined gradient of soil nutrient, silt and clay (SC) contents and elevation (He et al., 2007; Zuo et al., 2008). Topography partly affecting the distribution of soil properties indirectly influences vegetation composition (Zuo et al., 2008). However, these environmental factors are likely to affect the plant distributions at different spatial scales which are closely dependent on the habitats of plant growing (Chiarucci et al., 2001; Auestad et al., 2008).

Horqin Sandy Land is one of the most severely desertified regions in China (Liu et al., 1996). Since the 1970s, many effective measures have been taken to stabilize sand dunes and to restore degraded vegetation in areas of severe drifting sand, such as building physical sand barriers and corn straw fence belts, and placing wheat straw checkerboards on mobile dunes (Wang et al., 2004; Guo et al., 2008; Liu et al., 2009). In addition, due to the annual precipitation of 350-500 $\mathrm{mm}$, some mobile dunes can also be gradually and naturally restored to semi-fixed or fixed dunes after excluding livestock grazing (Zuo et al., 2009). Previous studies have shown that dune stabilization activities in semi-arid areas have led to distinct dune habitat types, including mobile dune in which sand pioneer plants are dominant species in barren soils, semi-fixed dune in which asexual reproduction perennial shrubs are dominant species, and fixed dune in which herbaceous plants are dominant species (Guo et al., 2008; Zuo et al., 2009; Yan and Liu, 2010; Yu et al., 2011). Many researches on species diversity and vegetation composition (Yan and Liu, 2010), topographical features (Shirato et al., 2005), soil properties (Raji et al., 2004; Zuo et al., 2010), biological soil crust (Guo et al., 2008), and relationship between species diversity and biomass (Zuo et al., 2012) in the processes of dune stabilization have been carried out. However, our knowledge on how environmental factors influence plant species richness at different spatial scales or habitats following dune stabilization degree is still lacking.

The objective of this study was to examine how environmental factors affect the scale dependence of plant species richness following dune stabilization degree. To achieve this objective, we tested three hypotheses: 1) plant species richness is spatial scale dependent in the processes of dune stabilization; 2) environmental factors determining plant species richness are different at various stages of dune stabilization; and 3) environmental gradients may influence plant species richness in dune stabilization. Such a study may further advance our understanding of the ecological consequences of dune stabilization in semi-arid areas.

\section{Materials and methods}

\subsection{Study area}

The study was conducted in the south-western part $\left(42^{\circ} 55^{\prime} \mathrm{N}, 120^{\circ} 42^{\prime} \mathrm{E}\right.$; $364 \mathrm{~m}$ asl) of Horqin Sandy Land, Inner Mongolia, China. The area is characterized by a temperate, semi-arid continental and monsoonal climate, receiving an average annual precipitation of 360 $\mathrm{mm}$, with $75 \%$ occurring in the growing season of June to September. The mean annual open-pan evaporation is about $1,935 \mathrm{~mm}$. The annual mean temperature is around $6.4^{\circ} \mathrm{C}$, with the minimum monthly mean temperature of $-13.1^{\circ} \mathrm{C}$ in January and the maximum of $23.7^{\circ} \mathrm{C}$ in July. The annual mean wind velocity is in the range of 3.2 to $4.1 \mathrm{~m} / \mathrm{s}$, and the prevailing wind directions are northwest in winter and spring, and southwest to south in summer and autumn 
(Liu et al., 1996; Zhang et al., 2005). The distribution pattern of the main natural vegetation is characterized by a mosaic of lowland grassland, fixed dune, semi-fixed and mobile dune. The zonal soil is identified as sandy chestnut soil, which is mostly equivalent to the Orthi-Sandic Entisols of sand origin in terms of the FAO-UNESCO system ( $\mathrm{Su}$ et al., 2006). The sandy land is covered with various native plants, including grasses (Cleistogenes squarrosa, Setaria viridis, Phragmites australis, Digitaria ciliaris), forbs (Mellissitus ruthenicus, Salsola collina, Agriophyllum squrrosum, Artemisia scoparia), shrubs (Lespedeza davurica), and subshrubs (Artemisia halodendron, Artemisia frigida).

\subsection{Experimental design}

Vegetation survey and field sampling were carried out in August 2009. Three major dune types at different dune stabilization stages were selected in typical areas of vegetation restoration by fencing after the mid1980s, including mobile dune, semi-fixed dune, and fixed dune, for which vegetation covers were less than $10 \%, 10 \%-50 \%$, and more than $50 \%$, respectively. Three replicate $20 \mathrm{~m} \times 50 \mathrm{~m}$ plots $0.6-8.0 \mathrm{~km}$ apart from each dune type and with similar topography were chosen to establish the modified Whittaker plot (MWP; Fig.1) (Stohlgren et al., 1999). Nested in the MWP were one $100-\mathrm{m}^{2}$ subplot $(5 \mathrm{~m} \times 20 \mathrm{~m})$ in the center and two $10-\mathrm{m}^{2}$ subplots $(5 \mathrm{~m} \times 2 \mathrm{~m})$ in opposite corners of the plot. Sixteen sampling quadrats (each $0.5 \mathrm{~m} \times 2$ $\mathrm{m}$ ) in each plot were regularly spaced within the MWP, six of which along the inner border of the $1,000-\mathrm{m}^{2}$ plot, and four and six along the outer border of the central $100-\mathrm{m}^{2}$ and $10-\mathrm{m}^{2}$ subplots, respectively (Zuo et al., 2012). In each quadrat, species richness (total number of species in a sampling area) and plant cover were measured. Species richness was recorded separately at each spatial scale and each plot. In addition, the altitude in each quadrat was recorded by a GPS receiver.

Concurrently, three soil samples were randomly collected within each quadrat at $0-20 \mathrm{~cm}$ depth using a $3 \mathrm{~cm}$-diameter soil auger, and were then pooled to form one composite sample for laboratory analysis. Soil samples were hand-sieved through a $2-\mathrm{mm}$ mesh to remove roots and other debris. Soil particle size from international and USDA classification systems was determined by the wet sieving method (Institute of Soil Sciences, Chinese Academy Sciences, 1978), including silt and clay (SC, $<0.05 \mathrm{~mm}, \%$ ), very fine sand (VFS, 0.05-0.10 mm, \%), fine sand (FS, $0.10-0.25 \mathrm{~mm}, \%$ ), and coarse sand (CS, 0.25-2.00 $\mathrm{mm}, \%$ ). Soil $\mathrm{pH}$ and electrical conductivity (EC) were measured in a 1:1 soil-water slurry and in a 1:5 soil-water aqueous extract, respectively. Soil organic carbon (SOC) was measured by the dichromate oxidation method of Walkey and Black (Nelson and Sommers, 1982) and total nitrogen (TN) was determined by the Kjeldahl procedure (Institute of Soil Sciences, Chinese Academy Sciences, 1978). With the same auger, the additional cores of three replicates were taken in each quadrat to measure soil water content (SWC) at 0-20 cm depth.

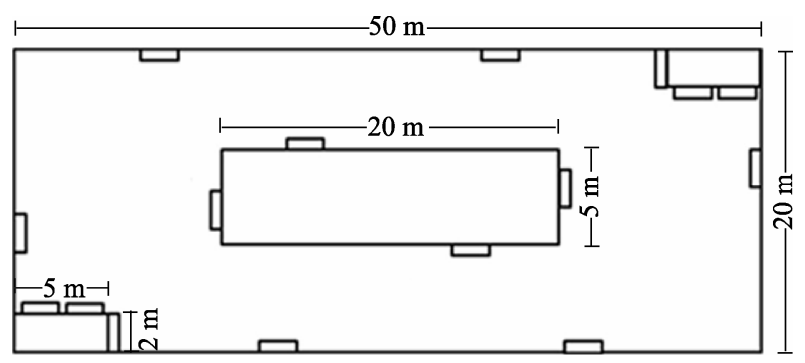

Fig. 1 Layout of the modified Whittaker plot (MWP) for experimental design and sampling

\subsection{Data analysis}

The effect of the dune stabilization degree on plant species richness across four multiple spatial scales $\left(1-1,000 \mathrm{~m}^{2}\right)$ was assessed using a general linear model with dune stabilization degree and spatial scale as fixed factors. Differences in soil properties among different dune stabilization stages were compared using the multiple comparison and one-way analysis of variance (ANOVA) procedures. Results were checked by Tukey's test $(P<0.01)$.

The relationships between vegetation composition and environmental factors were analyzed using the ordination technique. Data matrix of environmental factors and plant covers from 144 sampling quadrats were made separately along a gradient of dune stabilization. Canonical correspondence analysis (CCA) 
was used to examine the relationships of the floristic composition and the measured environmental variables along a gradient of dune stabilization. CCA is an effective ordination technique to analyze the vegetation-environment relationship (He et al., 2007; Zuo et al., 2009). In particular, the ordination diagram of samples, species and environmental variables from the CCA optimally displays how plant community composition varies with environmental factors (Chiarucci et al., 2001). Significance of species-environment correlation was tested by the distribution-free Monte Carlo test (1,000 permutations). Intra-set correlations from the CCA were used to assess the importance of the environmental variables.

The descriptive statistical parameters and significance test were calculated by SPSS version 19.0. The relationships between vegetation distribution and environmental factors were performed using the CANOCO 4.5 software.

\section{Results}

\subsection{Scale dependence of plant species richness}

Two treatments (i.e. dune stabilization degree and spatial scale) and their interaction significantly affected plant species richness (Table 1). Plant species richness increased significantly with the increases in spatial scales from 1 to $1,000 \mathrm{~m}^{2}$ in mobile dune, semi-fixed dune and fixed dune (Fig. 2). Plant species richness over all scales also increased significantly along the gradient of dune stabilization. In addition, the slopes of the species-area relationships changed with the various of dune stabilization degrees.

\subsection{Changes of environmental factors}

Differences in SOC, TN, carbon/nitrogen $(\mathrm{C} / \mathrm{N}), \mathrm{EC}$, FS, VFS and SC were obvious among the three different stages of dune stabilization $(P<0.05$; Table 2$)$. The average values of SOC, TN, C/N, EC, VFS and $\mathrm{SC}$ increased along the gradient of dune stabilization, but there was no significant difference in them between mobile dune and semi-fixed dune $(P>0.05$; Table 2). There was also no significant difference in SWC and altitude among different stages of dune stabilization ( $P>0.05$; Table 2).

\subsection{Relationships between vegetation composition and environmental factors}

The species-environment correlations were higher for the first two canonical axes, explaining $87.50 \%$ of the total cumulative variance (Table 3; Figs. 3 and 4). The first axis was significantly correlated to SOC, TN, $\mathrm{C} / \mathrm{N}, \mathrm{pH}, \mathrm{EC}, \mathrm{SWC}, \mathrm{FS}, \mathrm{VFS}, \mathrm{SC}$ and altitude $(P<0.01)$, and the second axis was significantly correlated to SOC, TN, C/N, EC, CS, VFS, SC and altitude $(P<0.01)$. A Monte-Carlo permutation test indicated that all the canonical axes were significant $(P<0.005)$.

The relationships between vegetation composition and environmental factors become more clear in the CCA ordination biplots (Figs. 3 and 4). The patterns presented on ordination diagrams indicated that a major gradient relating soil properties and altitude was associated with vegetation distribution. Sampling quadrats in fixed dune were associated with the SOC, $\mathrm{TN}, \mathrm{C} / \mathrm{N}, \mathrm{EC}, \mathrm{SWC}, \mathrm{CS}, \mathrm{VFS}$ and SC, in which the characteristic species are the plants of grass, forbs and perennial shrubs (e.g. Cleistogenes squarrosa, Ar-

Table 1 General linear model of the effects of dune stabilization degree and survey area on plant species richness

\begin{tabular}{cccrrr}
\hline Source & Type III sum of squares & $d f$ & Mean square & \multicolumn{1}{c}{$F$} & \multicolumn{1}{c}{$P$} \\
\hline Corrected model & $2,045.43$ & 11 & 185.95 & 35.23 & $<0.001$ \\
Intercept & $4,955.69$ & 1 & $4,955.69$ & 938.83 & $<0.000$ \\
Dune stabilization degree & $1,196.21$ & 2 & 598.10 & 113.31 & $<0.001$ \\
Area & 707.76 & 3 & 235.92 & 44.69 & $<0.001$ \\
Dune stabilization degree $\times$ area & 141.47 & 6 & 23.58 & 4.47 & 0.004 \\
Error & 126.69 & 24 & 5.28 & & \\
Total & $7,127.81$ & 36 & & & \\
\hline
\end{tabular}

Note: Significant $P$ values $(P<0.01)$ are in the $6^{\text {th }}$ column. 
temisia scoparia, Bassia dasyphylla, Caragana microphylla, Atraphaxis manshurica, Chenopodium acuminatum, and Salsola collina). Sampling quadrats in semi-fixed dune were associated with $\mathrm{FS}$ and $\mathrm{pH}$, in which the characteristic species are asexual reproduction perennial shrubs and annual herbaceous plants (e.g. Artemisia halodendron, Corispermum macrocarpum, and Ixetis chinensis). Plant communities in mobile dune are in the left quadrats of the biplots and are associated to the infertile soil and altitude, in which the characteristic species is Agriophyllum squarrosum (a pioneer dune plant).

\subsection{Correlation analysis between plant species richness and environmental factors}

Correlation analysis between plant species richness at a $1-\mathrm{m}^{2}$ scale and environmental factors indicated that species richness was significantly positive correlated to SOC and TN in mobile dune $(P<0.01)$, significantly positive correlated to $\mathrm{SOC}, \mathrm{TN}, \mathrm{C} / \mathrm{N}, \mathrm{VFS}$ and $\mathrm{SC}$ in semi-fixed dune $(P<0.01)$, and significantly negative correlated to SWC in semi-fixed dune $(P<0.01$; Table 4). However, there was no significant correlation between plant species richness and environmental factors in fixed dune $(P>0.05)$. The correlation analysis also showed that plant species richness was correlated with environmental gradients in the first and second axis from CCA (Fig. 5).

\section{Discussion}

The average values of plant species richness at a $1,000-\mathrm{m}^{2}$ scale in semi-fixed dune and fixed dune in Horqin Sandy Land were respectively 17.3 and 29.3, higher than those in desert plant community in western China (15.2; He et al., 2006), while mean plant species richness in mobile dune was lower (8.3). These results suggest that dune ecosystems in the semi-arid areas, especially semi-fixed dune and fixed dune which have relative good habitat conditions, have higher species diversity values than the desert ecosystems. Our results also showed that plant species richness increased with the development of dune sta-

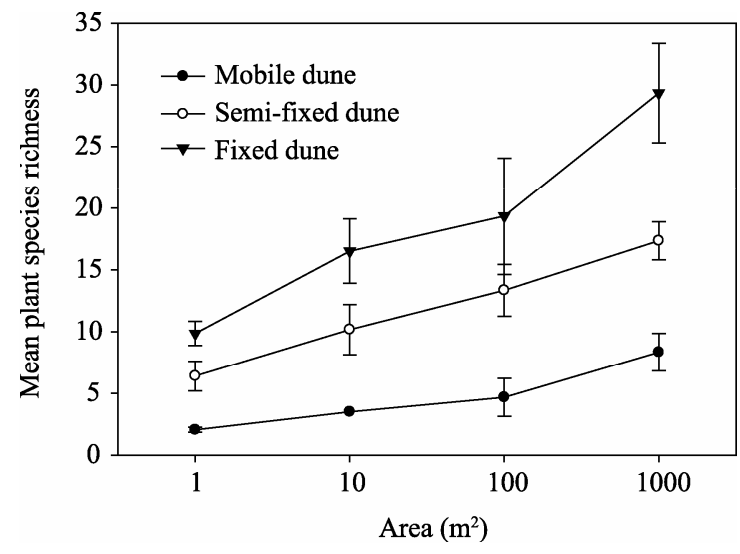

Fig. 2 Species-area relationships at different dune stabilization stages. Each error bar indicates one standard error for each combination of dune type and area.

Table 2 Comparison of soil properties and altitude at 1,000- $\mathrm{m}^{2}$ spatial scale among different dune stabilization stages

\begin{tabular}{crrrrr}
\hline Environmental factor & Mobile dune & Semi-fixed dune & Fixed dune & $F$ & $P$ \\
\hline SOC (g/kg) & $0.60 \pm 0.06^{\mathrm{a}}$ & $1.41 \pm 0.50^{\mathrm{a}}$ & $6.74 \pm 1.32^{\mathrm{b}}$ & 50.497 & 0.000 \\
$\mathrm{TN}(\mathrm{g} / \mathrm{kg})$ & $0.07 \pm 0.01^{\mathrm{a}}$ & $0.13 \pm 0.03^{\mathrm{a}}$ & $0.42 \pm 0.05^{\mathrm{b}}$ & 105.943 & 0.000 \\
$\mathrm{C} / \mathrm{N}$ & $8.07 \pm 1.02^{\mathrm{a}}$ & $11.09 \pm 1.92^{\mathrm{a}}$ & $16.13 \pm 1.30^{\mathrm{b}}$ & 23.258 & 0.001 \\
$\mathrm{pH}$ & $7.17 \pm 0.09^{\mathrm{ab}}$ & $7.24 \pm 0.16^{\mathrm{b}}$ & $6.93 \pm 0.10^{\mathrm{ac}}$ & 5.634 & 0.042 \\
EC ( $\mu \mathrm{s} / \mathrm{cm})$ & $10.29 \pm 0.53^{\mathrm{a}}$ & $16.69 \pm 1.85^{\mathrm{a}}$ & $27.77 \pm 5.92^{\mathrm{b}}$ & 18.168 & 0.003 \\
SWC (\%) & $2.08 \pm 0.40^{\mathrm{a}}$ & $1.19 \pm 0.50^{\mathrm{a}}$ & $2.76 \pm 0.95^{\mathrm{a}}$ & 4.274 & 0.070 \\
CS (\%) & $24.57 \pm 5.49^{\mathrm{a}}$ & $19.09 \pm 1.60^{\mathrm{a}}$ & $26.05 \pm 1.90^{\mathrm{a}}$ & 3.338 & 0.106 \\
FS (\%) & $71.78 \pm 5.74^{\mathrm{a}}$ & $74.64 \pm 2.15^{\mathrm{a}}$ & $53.98 \pm 1.50^{\mathrm{b}}$ & 28.325 & 0.001 \\
VFS (\%) & $3.26 \pm 0.09^{\mathrm{a}}$ & $4.98 \pm 1.98^{\mathrm{a}}$ & $13.15 \pm 0.38^{\mathrm{b}}$ & 61.705 & 0.000 \\
SC (\%) & $0.14 \pm 0.07^{\mathrm{a}}$ & $1.02 \pm 0.75^{\mathrm{a}}$ & $6.03 \pm 1.26^{\mathrm{b}}$ & 42.211 & 0.000 \\
Altitude (m) & $366.00 \pm 3.60^{\mathrm{a}}$ & $362.67 \pm 2.08^{\mathrm{a}}$ & $363.00 \pm 0.00^{\mathrm{a}}$ & 1.750 & 0.252 \\
\hline
\end{tabular}

Note: SOC, soil organic carbon; TN, total nitrogen; C/N, carbon/nitrogen; EC, electrical conductivity; SWC, soil water content; CS, coarse sand; FS, fine sand; VFS, very fine sand; SC, silt and clay. Different letters indicate statistical difference between dune stabilization types at $P<0.05$. 
Table 3 Intra-set correlations of the environmental variables, eigenvalues, species-environment correlation coefficients, and cumulative percentage variances for the first four axes of canonical correspondence analysis (CCA)

\begin{tabular}{|c|c|c|c|c|}
\hline & \multicolumn{4}{|c|}{ Axis } \\
\hline & SPX1 & SPX2 & SPX3 & SPX4 \\
\hline SOC & $-0.84^{* *}$ & $-0.29^{* *}$ & -0.10 & 0.05 \\
\hline $\mathrm{TN}$ & $-0.88^{* *}$ & $-0.31^{* *}$ & -0.11 & 0.04 \\
\hline $\mathrm{C} / \mathrm{N}$ & $-0.84^{* *}$ & $-0.49^{* *}$ & -0.07 & 0.01 \\
\hline $\mathrm{pH}$ & $0.51^{* *}$ & -0.03 & 0.14 & -0.07 \\
\hline $\mathrm{EC}$ & $-0.76^{* *}$ & $-0.41^{* *}$ & -0.15 & 0.08 \\
\hline SWC & $-0.40^{* *}$ & 0.17 & -0.10 & -0.20 \\
\hline $\mathrm{CS}$ & -0.18 & $0.24^{* *}$ & 0.10 & 0.03 \\
\hline FS & $0.74^{* *}$ & 0.08 & -0.03 & -0.03 \\
\hline VFS & $-0.89^{* *}$ & $-0.33^{* *}$ & -0.03 & 0.00 \\
\hline $\mathrm{SC}$ & $-0.88^{* *}$ & $-0.31^{* *}$ & -0.06 & 0.05 \\
\hline Altitude & $0.42^{* *}$ & $0.62^{* *}$ & $0.45^{* *}$ & 0.09 \\
\hline Eigenvalue & 0.691 & 0.340 & 0.032 & 0.030 \\
\hline $\begin{array}{l}\text { Species-environment } \\
\text { correlation coefficient }\end{array}$ & 0.962 & 0.739 & 0.595 & 0.606 \\
\hline $\begin{array}{c}\text { Cumulative percentage } \\
\text { variance }(\%)\end{array}$ & 58.70 & 87.50 & 90.20 & 92.70 \\
\hline
\end{tabular}

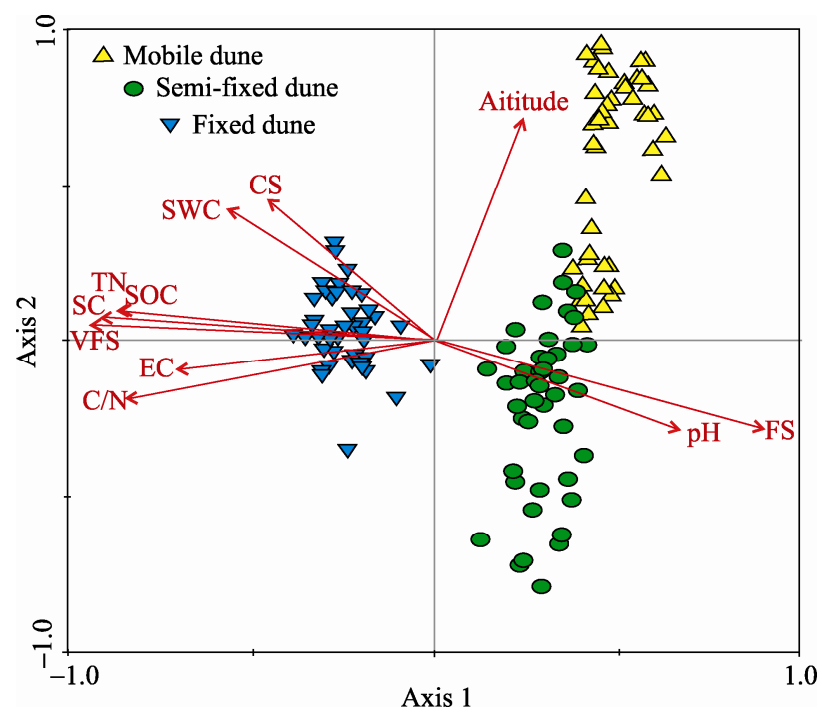

Fig. 3 CCA two-dimensional ordination diagram of the first two axes showing the distribution of 144 sampling quadrats and environmental variables (vectors; abbreviations are as defined in Table 2)

bilization stages, supporting that dune stabilization has an important role in the restoration and succession of degraded vegetation (Su et al., 2005; Guo et al., 2008; Zuo et al., 2009). In addition, we found that the effect of dune stabilization on plant species richness was scale-dependent, which is consistent with other studies in desert or grassland ecosystems (Crawley and Harral, 2001; He et al., 2006; Palmer, 2006). However, the scale dependence of plant species richness occurring in a sandy land ecosystem is higher than that in a desert ecosystem (He et al., 2006). These results suggest that scale dependence of species diversity is obviously different between sandy land ecosystems and desert ecosystems due to different environmental contexts.

Our results showed that plant distributions along the gradient of dune stabilization were determined by the combined environmental gradients in relation to SOC, TN, C/N, pH, EC, SWC, FS, VFS, SC and altitude, which is consistent with our previous studies (Zuo et al., 2008), supporting that soil properties and topographic features have an integrated influence in

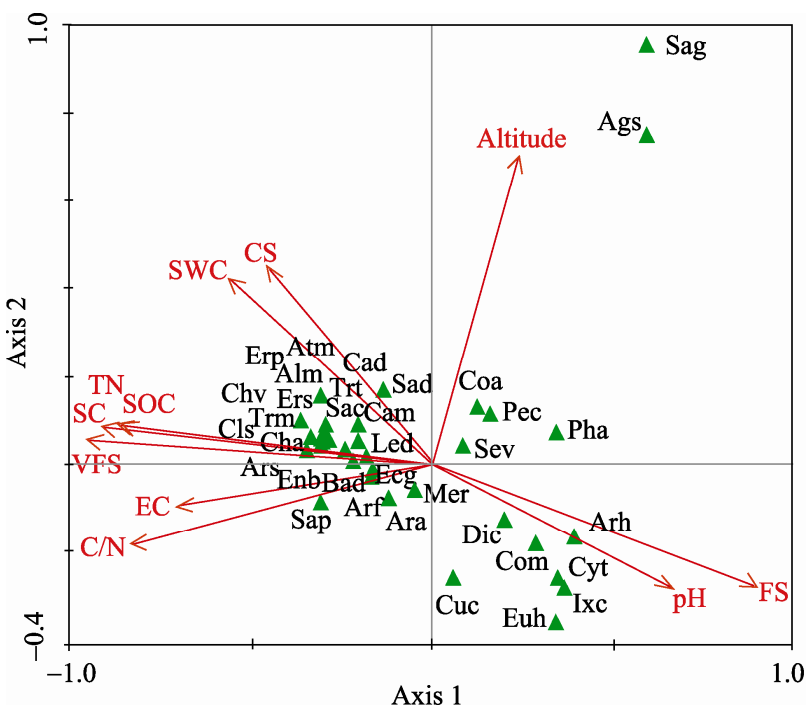

Fig. 4 CCA two-dimensional ordination diagram of the first two axes showing the distribution of 35 species (triangles and abbreviated Latin names) and environmental variables (vectors; abbreviations are as defined in Table 2). Ags, Agriophyllum squarrosum; Alm, Allium mongolicum; Ara, Aristida adscensionis; Arf, Artemisia frigida; Arh, Artemisia halodendron; Ars, Artemisia scoparia; Atm, Atraphaxis manshurica; Bad, Bassia dasyphylla; Cad, Carex dispalata; Cam, Caragana microphylla; Cha, Chenopodium acuminatum; Chv, Chloris virgata; Cls, Cleistogenes squarrosa; Coa, Convolvulus arvensis; Com, Corispermum macrocarpum; Cuc, Cuscuta chinensis; Cyt, Cynanchum thesioides; Dic, Digitaria ciliaris; Ecg, Echinops gmelini; Enb, Enneapogon brachystachyus; Erp, Eragrostis pilosa; Ers, Erodium stephanianum; Euh, Euphorbia humifusa; Ixc, Ixeris chinensis; Led, Lespedeza davurica; Mer, Melissitus ruthenicus; Pec, Pennisetum centrasiaticum; Pha, Phragmites australis; Sac, Salsola collina; Sad, Saposhnikovis divanicate; Sag, Salix gorodejevii; Sap, Salsola pellucida; Sev, Setaria viridis; Trm, Tragus mongolorum; Trt, Tribulus terrestris. 
Table 4 The relationships between plant species richness and environmental factors in different dune stabilization stages ( $n=48)$

\begin{tabular}{lccccccccccc}
\hline & SOC & TN & C/N & pH & EC & SWC & CS & FS & VFS & SC & Altitude \\
\hline Mobile dune & & & & & & & & & & \\
Plant species richness & $0.43^{* *}$ & $0.40^{* *}$ & $0.32^{*}$ & 0.14 & -0.05 & 0.14 & -0.13 & 0.12 & -0.04 & 0.20 & -0.07 \\
$\begin{array}{l}\text { Semi-fixed dune } \\
\text { Plant species richness }\end{array}$ & $0.38^{* *}$ & $0.37^{* *}$ & $0.43^{* *}$ & $0.29^{*}$ & 0.14 & $-0.58^{* *}$ & -0.26 & 0.00 & $0.48^{* *}$ & $0.48^{* *}$ & 0.28 \\
$\begin{array}{l}\text { Fixed dune } \\
\text { Plant species richness }\end{array}$ & -0.08 & -0.13 & 0.02 & 0.00 & -0.10 & -0.01 & 0.15 & -0.17 & 0.03 & 0.05 & 0.00 \\
\hline
\end{tabular}

Note: ${ }^{*}$ and ${ }^{* *}$ mean correlation significant at the 0.05 level (2-tailed) and 0.01 level (2-tailed), respectively. Abbreviations are as defined in Table 2.
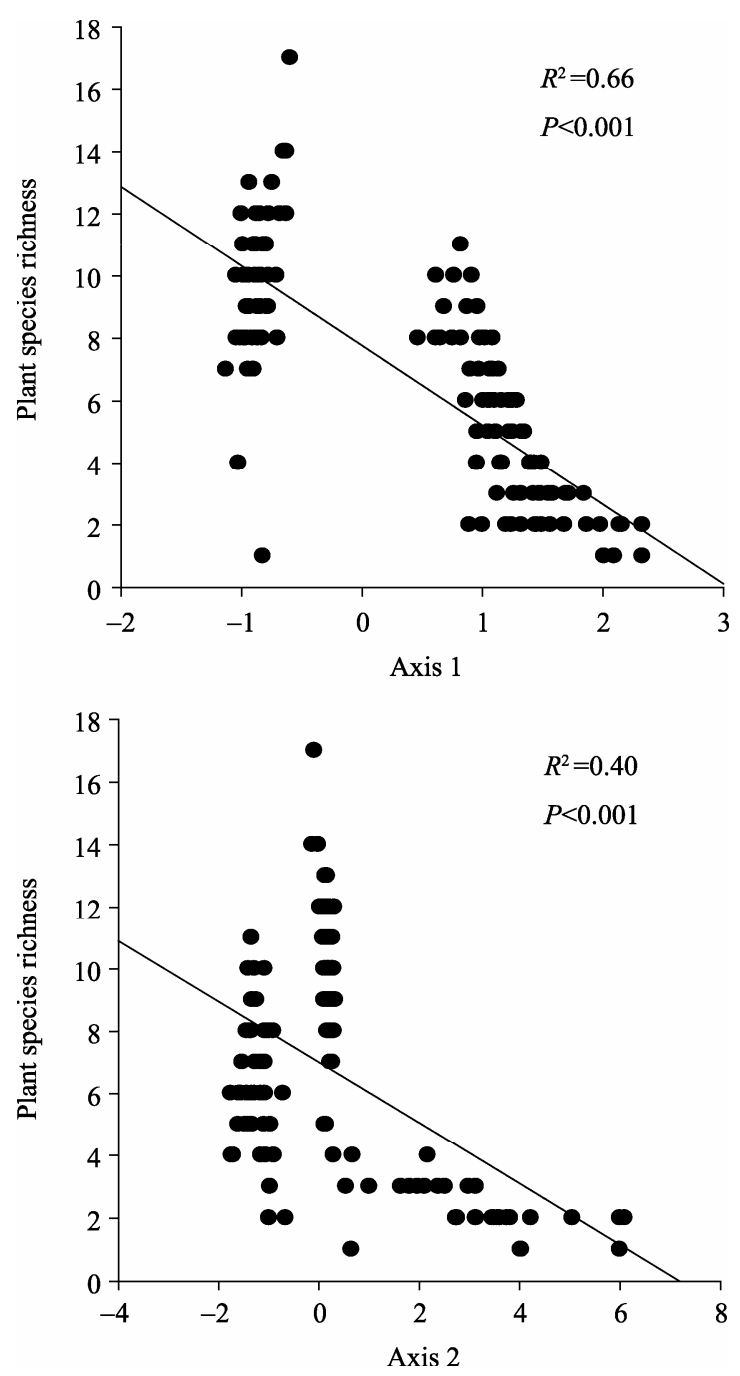

Fig. 5 Correlation analysis between plant species richness and environmental gradients in the first and second axis from CCA

vegetation composition (Moustafa and Zaghloul, 1996; He et al., 2007). The pioneer plant of Agriophyllum squarrosum in the sandy land can endure sand burial, survive barren soils and become the dominant species on top of mobile dunes, resulting in a decrease in the mobility of the soil surface (Zhang et al., 2005). Then, Artemisia halodendron, an asexual reproduction perennial shrub, invades into the community by seeds, and creates a nutrient-rich and water-retaining substrate under its canopy, providing a better environment for the establishment of herbaceous seedlings ( $\mathrm{Su}$ et al., 2005). So, herbaceous plants depending on soil nutrients under shrub canopies may start to spread and establish gradually on semi-fixed dunes, and shrub species gradually disappeared with dune stabilization from semi-fixed dunes to fixed dunes (Zhang et al., 2005). At the same time, the development of herbaceous plants has also an important role in soil development through the accumulation of organic litter, which further significantly improves the soil properties and supports the establishment of more dominant herbaceous plants on fixed dunes (Zuo et al., 2009).

Our results also showed that plant species richness increased with increasing spatial scales following dune stabilization degrees. The increase in plant species richness with spatial scale may be explained by the varying degrees of environmental factors at a given spatial scale (Spiegelberger et al., 2006). Correlation analysis showed that plant species richness had different correlations with environmental factors in the three different dune stabilization stages, suggesting that the effect of environmental factors on plant species richness strongly depends on the degree of dune stabilization. In addition, our results also suggest that with the increase of dune stabilization degree, semi-fixed dune and fixed dune are probably the more suitable habitats for the development and establishment of more plant populations with increasing spatial 
scales because of their relative better environmental conditions (Guo et al., 2008; Yan and Liu, 2010).

Due to the lower vegetation cover and litter accumulation on mobile dunes, long-term wind erosion causes soil coarsening and loss of soil nutrients, and increases the spatial and temporal variations of soil properties (Zhao et al., 2008), making SOC and TN become two most important factors for determining plant species richness. Then, establishment of $A r$ temisia halodendron and its effect of 'fertility island' improve the soil physical and chemical properties on semi-fixed dunes ( $\mathrm{Su}$ et al., 2005), so that SOC, TN, $\mathrm{C} / \mathrm{N}, \mathrm{VFS}$ and $\mathrm{SC}$ are important environmental factors influencing plant species richness. However, our previous study suggests that soil properties have higher spatial homogeneity on fixed dunes (Zuo et al., 2009), so that there is no relationship between plant species richness and environmental factors. Herbaceous species have obvious dominance on fixed dunes, which can be probably explained by species competition, a much more important factor in high-productivity habitats that is possible to drive species to dominate in these habitats (Abrams, 1995). This indicates that soil factors affecting plant distributions are closely dependent on the habitats of plant growing (Chiarucci et al., 2001; Auestad et al., 2008).

\section{Conclusions}

Our study supported the three hypotheses we tested and also demonstrated that plant species richness has obvious scale dependence along the gradient of dune stabilization degrees. Plant species richness, SOC, TN, $\mathrm{C} / \mathrm{N}, \mathrm{EC}, \mathrm{VFS}$ and SC increased consistently with dune stabilization degrees. Plant distributions along the gradient of dune stabilization were determined by the combined environmental gradient in relation to soil properties and altitude. Soil properties play an important role as key determiner by modifying the effect of dune stabilization on plant diversity. This finding emphasizes the importance of dune stabilization effects on plant species diversity, especially at different spatial scales. Maintaining dune stabilization appears to be the most promising approach to conserve high plant species diversity in sandy land eco- systems. So, it is necessary to make efforts to promote dune stabilization with protective measures, to avoid soil degradation, and to enhance natural restoration succession.

\section{Acknowledgements}

This paper was financially supported by the National Natural Science Foundation of China (41171414), the Knowledge Innovation Program of the Chinese Academy of Sciences (KZCX2-EW-QN313), the Chinese Academy of Sciences Visiting Professorships for Senior International Scientists (2011T2Z36), the Key Project of Scientific and Technical Supporting Programs (2011BAC07B02-09), and the National Basic Research Program of China (2009CB421303). We thank all the members of Naiman Desertification Research Station, Chinese Academy of Sciences, for their help in field work. We also wish to thank the reviewers for their valuable comments on the manuscript.

\section{References}

Abrams P A. 1995. Monotonic or unimodal diversity-productivity gradients: what does competition theory predict. Ecology, 76: 2019-2027.

Auestad I, Rydgren K, Økland R H. 2008. Scale-dependence of vegetation-environment relationships in semi-natural grasslands. Journal of Vegetation Science, 19: 139-148.

Caballero I, Olano J M, Loidi J, et al. 2008. A model for small-scale seed bank and standing vegetation connection along time. Oikos, 117: 1788-1795.

Cantero J J, Leon R, Cisneros J M, et al. 1998. Habitat structure and vegetation relationships in central Argentina salt marsh landscapes. Plant Ecology, 137: 79-100.

Chiarucci A, Rocchini D, Leonzio C, et al. 2001. A test of vegetation-environment relationship in serpentine soils of Tuscany, Italy. Ecological Research, 16: 627-639.

Crawley M J, Harral J E. 2001. Scale dependence in plant biodiversity. Science, 291: 864-868.

Guo Y R, Zhao H L, Zuo X A, et al. 2008. Biological soil crust development and its topsoil properties in the process of dune stabilization, Inner Mongolia, China. Environmental Geology, 54: 653-662.

He M Z, Zheng J G, Li X R, et al. 2007. Environmental factors affecting vegetation composition in the Alxa Plateau, China. Journal of Arid Environments, 69: 473-489.

He Z B, Zhao W Z, Chang X X, et al. 2006. Scale dependence in desert plant diversity. Biodiversity and Conservation, 15: 3055-3064.

Institute of Soil Sciences, Chinese Academy of Sciences. 1978. Physical and Chemical Analysis Methods of Soils. Shanghai: Shanghai 
Science Technology Press

Kirkpatrick J B, Bridle K L. 1999. Environment and floristics of ten Australian alpine vegetation formations. Australian Journal of Botany, 47: 1-21.

Liu R T, Zhao H L, Zhao X Y, et al. 2009. Soil macrofaunal response to sand dune conversion from mobile dunes to fixed dunes in Horqin sandy land, northern China. European Journal of Soil Biology, 45: 417-422.

Liu X M, Zhao H L, Zhao A F. 1996. A Wind-Sandy Environment and Vegetation in the Horqin Sandy Land, China. Beijing: Science Press.

Marini L, Scotton M, Klimek S, et al. 2008. Patterns of plant species richness in Alpine hay meadows: Local vs. landscape controls. Basic and Applied Ecology, 9: 365-372.

Moustafa A E R A, Zaghloul M S. 1996. Environment and vegetation in the montane Saint Catherine area, south Sinai, Egypt. Journal of Arid Environments, 34: 331-349.

Palmer M W, White P S. 1994. Scale dependence and the species-area relationship. American Naturalist, 144: 717-740.

Palmer M W. 2006. Scale dependence of native and alien species richness in North American floras. Preslia, 78: 427-436.

Petersen S M, Drewa P B. 2009. Are vegetation-environment relationships different between herbaceous and woody groundcover plants in barrens with shallow soils? Ecoscience, 16: 197-208.

Qian Y B, Wu Z N, Zhao R F, et al. 2008. Vegetation patterns and species-environment relationships in the Gurbantunggut Desert of China. Journal of Geographical Sciences, 18: 400-414.

Raji B A, Uyovbisere E O, Momodu A B. 2004. Impact of sand dune stabilization structures on soil and yield of millet in the semi-arid region of NW Nigeria. Environmental Monitoring and Assessment, 99: 181-196.

Schooley R L. 2006. Spatial heterogeneity and characteristic scales of species-habitat relationships. BioScience, 56: 533-537.

Shirato Y, Zhang T H, Ohkuro T, et al. 2005. Changes in topographical features and soil properties after exclosure combined with sand-fixing measures in Horqin Sandy Land, Northern China. Soil Science and Plant Nutrition, 51: 61-68.

Spiegelberger T, Matthies D, Muller-Scharer H, et al. 2006. Scale-dependent effects of land use on plant species richness of mountain grassland in the European Alps. Ecography, 29: 541-548.

Su Y Z, Zhang T H, Li Y L, et al. 2005. Changes in soil properties after establishment of Artemisia halodendron and Caragana microphylla on shifting sand dunes in semiarid Horqin sandy land, Northern
China. Environmental Management, 36: 272-281.

Su Y Z, Li Y L, Zhao H L. 2006. Soil properties and their spatial pattern in a degraded sandy grassland under post-grazing restoration, Inner Mongolia, northern China. Biogeochemistry, 79: 297-314.

Turner W R, Tjorve E. 2005. Scale-dependence in species-area relationships. Ecography, 28: 721-730.

Wana D, Beierkuhnlein C. 2011. Responses of plant functional types to environmental gradients in the south-west Ethiopian highlands. Journal of Tropical Ecology, 27: 289-304.

Wang T, Wu W, Xue X, et al. 2004. Study of spatial distribution of sandy desertification in North China in recent 10 years. Science in China: Earth Sciences, 47: 78-88.

Weiher E, Howe A. 2003. Scale-dependence of environmental effects on species richness in oak savannas. Journal of Vegetation Science, 14: 917-920.

Yan S, Liu Z. 2010. Effects of dune stabilization on the plant diversity of interdune wetlands in Northeastern Inner Mongolia, China. Land Degradation \& Development, 21: 40-47.

Yu F H, Li S L, Werger M J A, et al. 2011. Habitat-specific demography across dune fixation stages in a semi-arid sandland: understanding the expansion, stabilization and decline of a dominant shrub. Journal of Ecology, 99: 610-620.

Zhang J, Zhao H, Zhang T, et al. 2005. Community succession along a chronosequence of vegetation restoration on sand dunes in Horqin Sandy Land. Journal of Arid Environments, 62: 555-566.

Zhao H L, Zhou R L, Li Y Q, et al. 2008. Desertification effects on C and $\mathrm{N}$ content of sandy soils under grassland in Horqin, northern China. Geoderma, 145: 370-375.

Zuo X A, Zhao X Y, Zhao H L, et al. 2009. Spatial heterogeneity of soil properties and vegetation-soil relationships following vegetation restoration of mobile dunes in Horqin Sandy Land, Northern China. Plant and Soil, 318: 153-167.

Zuo X A, Zhao X Y, Zhao H L, et al. 2010. Spatial pattern and heterogeneity of soil organic carbon and nitrogen in sand dunes related to vegetation change and geomorphic position in Horqin Sandy Land, Northern China. Environmental Monitoring and Assessment, 164: 29-42.

Zuo X A, Zhao X Y, Wang S K, et al. 2012. Influence of dune stabilization on relationship between plant diversity and productivity in Horqin Sand Land, Northern China. Environmental Earth Sciences, 67: 1547-1556. 